\title{
Editorial
}

\section{WOMEN IN PHARMACY}

Women in pharmacy is now an accomplished fact, and the keen desire of the close observer is that this condition become permanent. Apart from the present economic conditions, it is most desirable that women become permanently interested in the craft, as they have a natural adaptability to meet the requirements of the average pharmacy.

The immediate consideration is war necessities and demands. Man power will be the deciding factor in the great struggle now dominating the entire world, and the imperative demand on those nations standing as a united whole for the maintenance of freedom, liberty, righteousness and home is to furnish the last available unit, that not only the ruthless destroyer be foiled in his attempt at world subjugation, but that the forces of evil be swept from the face of the earth.

In meeting the requirements of the demand, it is essential to future safety that the menace of entire dislocation of industries and business be guarded against and this can be accomplished only by the nonmilitary classes of the nation taking up the burdens laid down by the home defenders, and carrying on against the day of final adjustment. Of these classes, women are the major part, and they must of necessity, slip into the breach; and why not as experience has demonstrated their capabilities and adaptability in amost every line of commercial activity.

Pharmacy just now is among the industries facing an acute situation due to the depletion of its ranks by military requirements. The first call met with such a spontaneous response by our members, that the number available under the MSA [Military Service Act] is limited. The going of these has faced the craft with a problem in the solving of which women must bulk largely, and indications are that the "line will be held," as "women reserves" are coming. The Registrar-Treasurer of the OCP [Ontario College of Pharmacy] reports 35 registrations of women apprentices during the past six months, equal to one-third normal conditions, and we apprehend that similar conditions prevail in other provinces.

So much for the economic phase. The other features of adaptability and efficiency are equally conclusive. Women have trained hands for fine work, and in pharmaceutical manipulation are at home as soon as familiarity with apparatus is acquired. A woman's ability for taking infinite pains is admitted, and in pharmacy this characteristic finds room for full play. Their conscientious trustworthiness is beyond question, and in dependability they excell. Entrust an average woman with responsibility and it will either be declined, or discharged fully. The over-burdened pharmacist is ready to appreciate these qualities in assistants when such are available, as they are in women.

In the selling department the average woman excells, due to the readiness to please and intuitive knowledge of human nature. In service she is the last word in efficiency, all her characteristics combining to make her give of her best to the task in hand. Add to these her training in orderly neatness and cleanliness, and we have in woman the ideal pharmacist of the twentieth century, and one of the most desirable by-products of the war. 


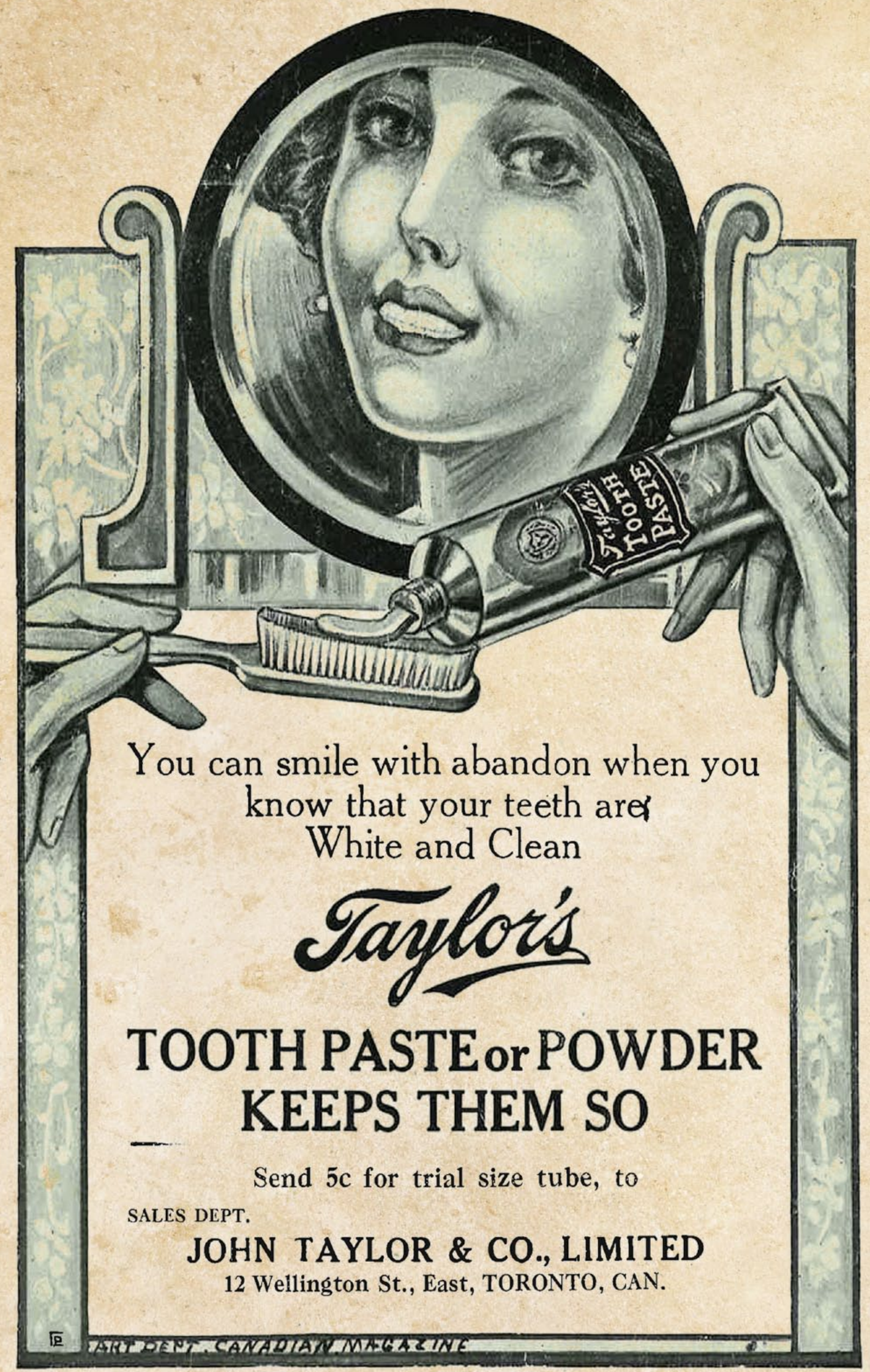

